\title{
BMJ Open Prevalence of birefringent crystals in cardiac and prostatic tissues, an observational study
}

\author{
Jane J Park, ${ }^{1}$ Martine P Roudier, ${ }^{2}$ Divya Soman, ${ }^{1}$ Nahush A Mokadam, ${ }^{3}$ \\ Peter A Simkin ${ }^{1}$
}

To cite: Park JJ, Roudier MP, Soman D, et al. Prevalence of birefringent crystals in cardiac and prostatic tissues, an observational study. BMJ Open 2014;4: e005308. doi:10.1136/ bmjopen-2014-005308

- Prepublication history for this paper is available online. To view these files please visit the journal online (http://dx.doi.org/10.1136/ bmjopen-2014-005308).

Received 24 March 2014 Revised 30 May 2014 Accepted 25 June 2014

\section{CrossMark}

${ }^{1}$ Department of Medicine (Rheumatology), University of Washington, Seattle, Washington, USA

${ }^{2}$ Ventana Medical Systems Inc, Tucson, Arizona, USA ${ }^{3}$ Department of Surgery (Cardiothoracic Surgery), University of Washington, Seattle, Washington, USA

Correspondence to Dr Peter A Simkin; psimkin@uw.edu

\section{ABSTRACT}

Introduction: The prevalence of urate crystals in residual tissue samples from coronary arteries, aortic valves and prostate glands was assessed.

Methods: Alcohol-fixed coronary arteries from 55 explanted hearts, alcohol-fixed aortic valves collected from 75 valve replacement surgeries and 40 frozen, unfixed prostate specimens resected during cancer surgery were examined for birefringent crystals with polarising microscopy.

Results: In the 55 explanted hearts, 6 (10.9\%) contained a coronary artery with birefringent crystals. One of the 75 aortic valves (1.4\%) contained negatively and positively birefringent crystals. Nineteen of the 40 $(47.5 \%)$ prostates contained birefringent crystals.

Conclusions: We found that a remarkable percentage of coronary arteries and prostate specimens contained birefringent crystals. Crystal presence is an obvious prerequisite for possible crystal induced-inflammation in these tissues, just as similar crystals elicit a gouty inflammatory cascade in synovial joints. Further studies are necessary to determine whether urate crystals may play this role in these tissues and, if so, to establish whether urate-lowering therapy may be beneficial in prostatitis and coronary disease.

\section{INTRODUCTION}

By definition, hyperuricaemic interstitial fluids are supersaturated, and urate supersaturation leads to precipitation of urate crystals. In joints, the crystals often drive the inflammatory disease recognised as gouty arthritis. However, hyperuricaemia is not limited to plasma and the joints. All other interstitial fluids (excepting cerebrospinal fluid and sweat) will be supersaturated as well. Consequently, urate crystals will occur in non-articular tissues and may well drive crystal-induced inflammation.

In fact, anecdotal observations of visible and/or palpable tophaceous deposits have been reported from many different organs, ${ }^{1}$ but they have usually been considered to be 'medical oddities'. ${ }^{2}$ Newer imaging modalities of ultrasound and dual-energy CT
Strengths and limitations of this study

- First study to systematically evaluate for the prevalence of urate crystals within tissues.

- First study to show a significant percentage of extra-articular negatively birefringent crystals.

- Secondary methods, aside from polarising microscopy, to confirm urate composition of the visualised crystals were unsuccessful.

- Clinical correlations were not possible for coronary and prostate samples since these were taken from anonymous repositories collected for nonrheumatic diseases.

(DECT) have revealed far more extensive periarticular deposition than we previously suspected. ${ }^{3-5}$ Until now, however, we have limited microscopic evidence of extraarticular urate deposition, and we do not know whether the published anecdotes are unique. As an initial venture into the field of crystal prevalence, we obtained access to unselected tissue specimens from coronary arteries, cardiac valves and prostate glands. At each of these sites, crystal-driven inflammation could play an important role in the local pathophysiology.

Gout and hyperuricaemia have been associated with hypertension, coronary artery disease and all-cause mortality, ${ }^{6-13}$ but the mechanisms responsible for these associations remain unclear. Atherosclerotic disease is a ubiquitous process involving plaque formation throughout the arterial tree. The formation of these lesions is now seen as a process of lipid deposition within the intima of the vessel wall, oxidation of the lipoproteins, followed by endothelial activation-resulting in leucocyte adhesion and migration into the vessel wall. ${ }^{14-16}$ The presumed pathways are complex, involving T cells, macrophages, neutrophils and dendritic cells, accumulation of apoptotic cells and ultimately to plaque formation, rupture and thrombosis. ${ }^{17-19}$

We suggest that urate crystals in the arterial intima of patients with gout could, in some 
cases, drive the inflammation that causes plaques to rupture and thereby factor in their cardiac risk. This role is well established in gouty joints where microcrystalline activation of the NALP3 inflammasome pathway induces multiple inflammatory mediators including interleukin-1 $\beta$ (IL-1 $\beta),{ }^{20}$ and leads to gouty arthritis. In sum, monosodium urate (MSU) crystal deposits within coronary arteries could potentially trigger a corresponding inflammatory cascade that eventuates in thrombosis and infarction.

We are aware of only one previous report of apparent urate crystals in a coronary artery. In that report, Traut et $a l^{21}$ describe a man with tophaceous gout who died of a ruptured abdominal aortic aneurysm with birefringent, spherulitic deposits in the intima of a coronary artery on autopsy. This report preceded the application of first-order red plates, ${ }^{22}$ so it is not known whether the crystalline deposits were negatively birefringent, as urate crystals are, or positively birefringent, as calcium pyrophosphate crystals are.

In contrast to the rarity of arterial crystals, multiple reports of cardiac valvular tophi have been published. ${ }^{23-28}$ Presumably, individual MSU crystals must also deposit on the valves, though their presence has not been described. Aortic stenosis is a common cause of valvular disease, with calcific stenosis prevalence increasing with age to approximately $2.8 \%$ in ages $\geq 75$ years. ${ }^{29}$ Aortic valve degeneration is also associated with male gender, hypertension and metabolic syndrome, ${ }^{30} 31$ all risk factors associated with hyperuricaemia and gout. Additionally, higher serum uric acid levels have been described in patients with severe calcific aortic stenosis compared to mild or moderate aortic stenosis. ${ }^{32}$

Finally, chronic non-bacterial prostatitis or chronic pelvic pain syndrome (CPPS), a condition characterised by chronic pelvic pain of unidentifiable cause for greater than three of the preceding 6 months, is a common problem, affecting $2-10 \%$ of men. ${ }^{33}$ Effective treatment remains elusive, and the condition is frustrating to physicians as well as affected patients. Various aetiologies have been proposed, including occult infection, neurological dysfunction, psychological factors and immune dysregulation. ${ }^{34}$ The role of inflammation remains controversial, as the presence of leucocytes on prostate biopsy does not correlate with the severity of symptoms. ${ }^{35}$ However, molecular studies have shown increased cytokine levels in patients with CPPS, including IL-8, CXCL5 or epithelial neutrophil activating peptide 78 (ENA-78), ${ }^{36}$ tumour necrosis factor- $\alpha$ and, interestingly, IL-1 $\beta .^{37}$ In addition, a study of expressed prostatic secretions in 56 men with chronic prostatitis found that higher urate concentrations correlated with prostatic symptoms, though the specimens were not examined for crystals. ${ }^{38}$ The authors then performed a placebocontrolled trial of allopurinol at 300 or $600 \mathrm{mg}$ a day in 54 men for 8 months. The allopurinol-treated patients demonstrated statistically significant lower urate levels in expressed prostatic secretions as well as improved subjective pain compared to the placebo group. $^{39}$ To the best of our knowledge, MSU crystals have not been sought or identified in prostate tissue prior to our present study.

Given the evidence that tophaceous MSU deposition is widespread and that hyperuricaemia now approaches epidemic proportions, we suspected that subclinical, microscopic deposition must also be widespread. To address this suspicion, we carried out a pilot crystal prevalence study in three human conditions where appropriate tissue samples were available and chronic inflammation remains problematic: coronary disease, aortic stenosis and chronic prostatitis.

\section{METHODS}

\section{Coronary artery evaluation}

Coronary arteries (left anterior descending, right coronary, left main and circumflex) fixed in methacarn $(60 \%$ absolute methanol (Sigma-Aldrich, St Louis, Missouri, USA), 30\% chloroform (Sigma-Aldrich, St Louis, MO), $10 \%$ glacial acetic acid (Sigma-Aldrich, St Louis, Missouri, USA)) obtained from 55 explanted hearts at the time of heart transplant conducted from 2000 to 2003 at the University of Washington Medical Center were examined with polarising microscopy (Olympus BX50, Tokyo, Japan) and photographed (Canon EOS 5D Mark II, Tokyo, Japan). Three to six consecutive sections of each artery were examined. To be considered positive, visualised crystals had to be present in two or more sections of the same specimen. Deconvolution microscopy (Zeiss 510 META, Oberkochen, Germany) was used to verify the intracellular nature of the crystals in one specimen. Clinical records of these individual patients were not available as the specimens had been de-identified as required by the University of Washington Institutional Review Board. Since the clinical indications for cardiac transplantation have not changed, we carried out a demographic review of 50 consecutive patients undergoing heart transplantation from January 2010 to March 2012 (table 1). Of these 50 patients, $19(38 \%)$ had a history of gout and $24(48 \%)$ were hyperuricaemic (serum uric acid $>7 \mathrm{mg} / \mathrm{dL}$ ).

\section{Aortic valve evaluation}

Seventy-five aortic valves obtained from aortic valve replacement conducted from 2011 to 2013 were fixed in methacarn, decalcified in RDO acid (Apex Engineering, Plainfield, Illinois, USA) and examined with polarising microscopy. Four consecutive sections were examined for each valve. To be considered positive, visualised crystals had to be present in two or more sections of the same specimen. Clinical information for these patients was available for review though serum urate was known for only four participants. Eight of the 75 (10.7\%) patients had a history of gout, $6(8 \%)$ were on allopurinol, $31(41.3 \%)$ were on diuretics and $17(22.7 \%)$ had renal insufficiency. Three patients $(4.0 \%)$ had an serum 
Table 1 Clinical characteristics of patients with heart transplant from 2010 to 2012

\begin{tabular}{lrc}
\hline & N & Per cent \\
\hline Gender & & \\
$\quad$ Males & 40 & 80 \\
$\quad$ Females & 10 & 20 \\
Age (years) & & \\
$19-29$ & 4 & 8 \\
$30-39$ & 2 & 4 \\
$40-49$ & 10 & 20 \\
$50-59$ & 20 & 40 \\
$60-69$ & 14 & 28 \\
$>70$ & 0 & 0 \\
Gout & 19 & 38 \\
Hyperuricaemia & 24 & 48 \\
(serum uric acid >7 mg/dL) & & \\
Urate lowering therapy & 16 & 32 \\
Diuretic use & 34 & 68 \\
Chronic kidney disease & 30 & 60 \\
Indication for transplant & & \\
$\quad$ Ischaemic cardiomyopathy & 19 & 38 \\
Dilated cardiomyopathy & 18 & 36 \\
Other & 13 & 26 \\
\hline Corona arterios for this study were &
\end{tabular}

Coronary arteries for this study were collected from heart transplants occurring from 2000 to 2003.

urate level $>7 \mathrm{mg} / \mathrm{dL}$, and all three of these patients also carried a diagnosis of gout.

\section{Prostate evaluation}

Forty frozen and unfixed, prostates from consecutive radical prostatectomies performed for prostate cancer from 2012 to 2013 were assessed. Non-malignant regions were evaluated with polarising microscopy. One section from each prostate was examined. H\&E stained serial sections were examined independently for inflammatory foci in a blinded fashion. Inflammation was graded on a scale of I-IV based on the number of inflammatory foci consisting of mononuclear infiltrates, giant cells and/or polymorphonuclear cells. Grade I was assigned for 1-2 foci, grade II for 3-4 foci, grade III for 4-5 foci and grade IV for 6 or more foci of inflammatory cells within the section.

None of the patients had a recorded history of chronic prostatitis, gout, urate-lowering therapy or hyperuricaemia.

The University of Washington Institutional Review Board approved our crystal-prevalence study.

\section{RESULTS}

\section{Coronary artery evaluation}

Of the 55 hearts examined, 6 arteries from different hearts $(10.9 \%)$, contained birefringent crystals. One patient had intracellular, negatively birefringent, acicular crystals in the intima of the left anterior descending (figure 1). One patient had a microtophus in the intima of the left anterior descending (figure 2). One patient had negatively birefringent crystals and microtophi in the adventitia of the right coronary artery (figure 3). Three additional patients had highly birefringent accumulations of intimal, extracellular unidentifiable crystals.

\section{Aortic valve evaluation}

Of the 75 aortic valves assessed, one valve (1.3\%) had positively and negatively birefringent crystals present scattered throughout.

\section{Prostate evaluation}

Nineteen of the 40 prostates $(47.5 \%)$ contained abundant, acicular (needle-shaped) birefringent crystals. The majority were negatively birefringent, though positively birefringent crystals were also seen. All crystals were present within the lumens of the glands (figure 4).

By severity of inflammation, crystals were seen in 5 of the 12 grade I specimens, 6 of 13 grade II specimens, 4 of 6 grade III specimens and 4 of 7 grade IV specimens. Thirty-eight specimens contained mononuclear infiltrates, nine with polymorphonuclear cells and one with giant cells. Thus, the presence of crystals did not correlate with inflammatory foci grade.

\section{CONCLUSIONS}

When serum is hyperuricaemic, so too are all other extracellular body fluids other than cerebrospinal fluid and sweat. Urate crystals are known to precipitate in loci other than the joints when supersaturated with uric acid. Anecdotal tophi have been reported in many different organs, ${ }^{1}$ though prevalence data of individual crystals are lacking. Are such deposits exceptional, or are they the tip of a crystalline iceberg?

Little data exist on the prevalence of tissue MSU crystal deposition in patients who do not have gout. An autopsy study of 1733 unselected Australian patients found that $8 \%$ of kidneys contained urate deposits, ${ }^{40}$ many from individuals with no known history of gout. In classic autopsy studies of 279 participants gout, Talbott ${ }^{41}$ found normal kidneys in only four, and gross crystalline deposits in many. In others, crystal presence could be ascertained by the gritty feeling when the kidneys were cut with a knife. ${ }^{2} \mathrm{~A}$ study of cadaveric first metatarsophalangeal joints found that $17 \%$ of 70 consecutive autopsies of men and women contained MSU crystals. Only two of the 12 patients with MSU crystals had a history of podagra or gout. ${ }^{42}$ With the advent of newer imaging modalities such as ultrasound and DECT, our understanding of urate deposition continues to evolve, ${ }^{3-5}$ but we know of no other studies of microscopic prevalence.

Our study demonstrates crystal deposition within a significant percentage of coronary arteries with one artery containing characteristic acicular, intracellular negatively birefringent crystals. In that specimen, one focus of mononuclear cells contained many with crystalline inclusions, but no polymorphonuclear leucocytes were seen. We are concerned that crystal-driven inflammation may 
Figure 1 Intracellular negatively birefringent crystals in the intima of a left anterior descending artery (left) as seen with polarising microscopy. White arrow denotes a first-order red plate axis. Deconvolution confocal microscopy image of the same cell showing intracellular crystals (right).

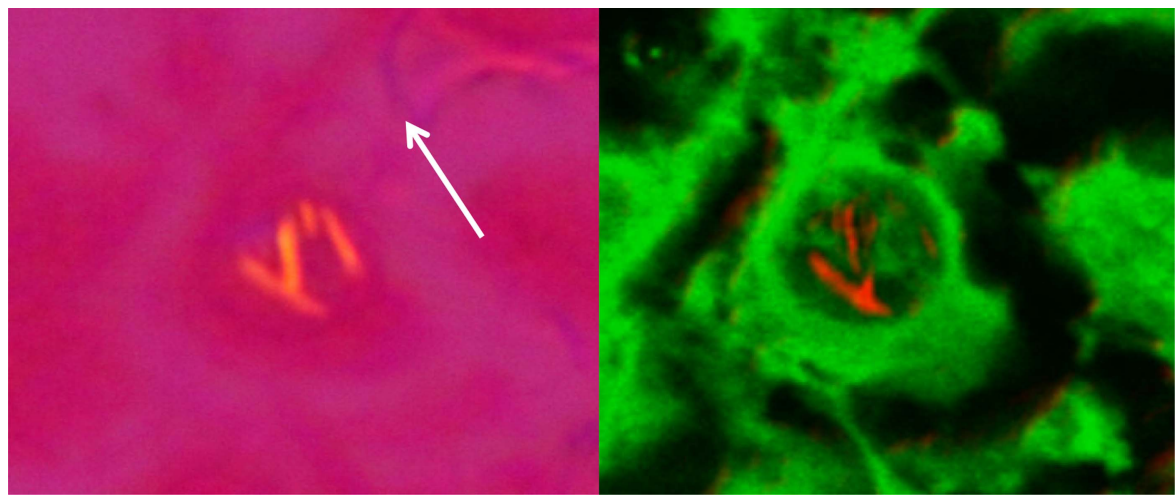

cause plaque rupture and coronary thrombosis in some patients with gout, but confirmation of that hypothesis requires intracellular crystals at the site of a fatal lesion. To make that observation, the pathologist must fix the tissue in alcohol (since formalin may extract tissue urate deposits) and then must examine the sections under polarised light. ${ }^{43}$ Neither alcohol fixation nor polarised microscopy is a standard procedure, but we hope that pathologists will use them as they evaluate the all too frequent lethal myocardial infarctions in gouty individuals.

Confirmation of crystal composition can be difficult in tissue sections. In contrast to the thin film seen by rheumatologists in synovial aspirates, most tissue slices are $\sim 7$ microns in thickness and this is about the length of the prototypic urate crystal. Most crystals will then angle away from the tissue plane and appear to be short with varying thickness. In addition, the cytoplasmic constituents above and below a crystal of interest will lead to light scattering with indistinct crystal borders. We suspect that these issues are the principal reasons why most of the reports of crystal deposits in non-articular locations are not illustrated by a photograph.

We further suspect that there is an as yet undefined alteration in the composition of urate deposits in some

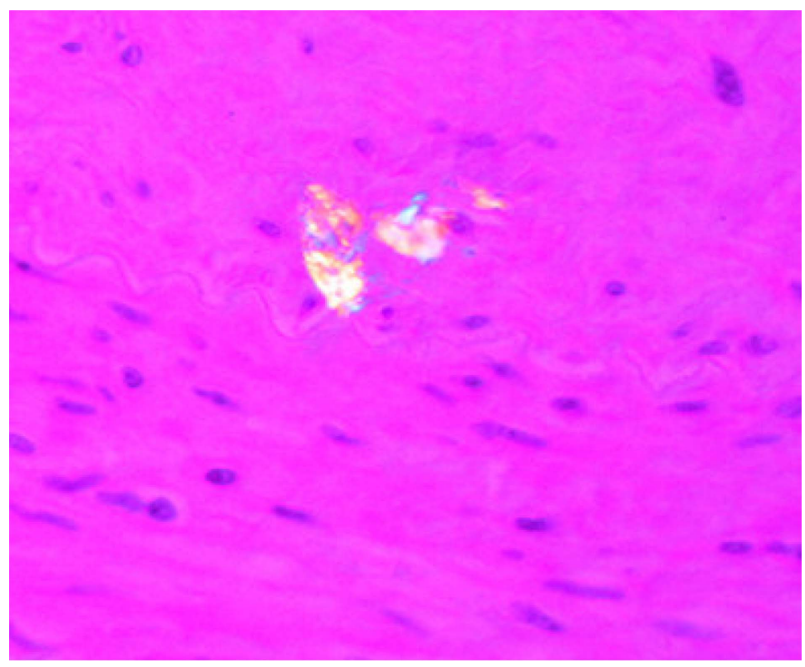

Figure 2 Microtophus in the intima of a left anterior descending artery. tissues. In some of the microtophi we have observed, the crystals occur not only in the classic needle and/or spherulite form but also as plates which sometimes stack on each other. Plate-like crystals have been described in tophi in addition to classic needle-shaped crystals in a case report. ${ }^{44}$ Additionally, Spitz et $a t^{45}$ in 1949 observed two morphological types of crystals in bony, cartilage and renal tophi in a man with diffuse tophaceous gout. Crystals with 'fine needles' in a 'radial arrangement' with surrounding giant cells, lymphocytes and fibroblasts were described. These typical crystals dissolved with formalin fixation, paraffin embedding and H\&E staining but did not dissolve with alcohol fixation and De Galantha staining. A second type of crystal remained after formalin fixation, paraffin embedding, H\&E staining and decalcification with weak acids (sodium citrate and formic acid). These were described as rhomboid, 'doubly refractive,' with 'longitudinal striations' and oriented in 'irregular clusters or sheaves of elongated blunt needles'. We have studied such deposits in slides from the kidney of a man with severe, tophaceous gout. The slides were decalcified so calcium crystals were unlikely. The deposits did not dissolve with topical uricase or formalin. They did not appear to be protein-coated since applied protease did not affect their resistance to uricase. They did stain positively with De Galantha's stain, though this stain for urate crystals is non-

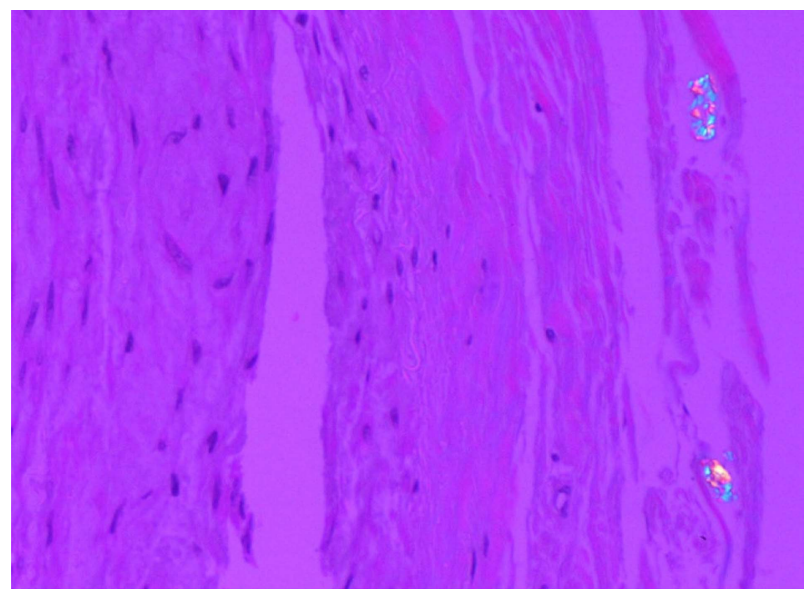

Figure 3 Microtophi in the adventitia of a right coronary artery. 


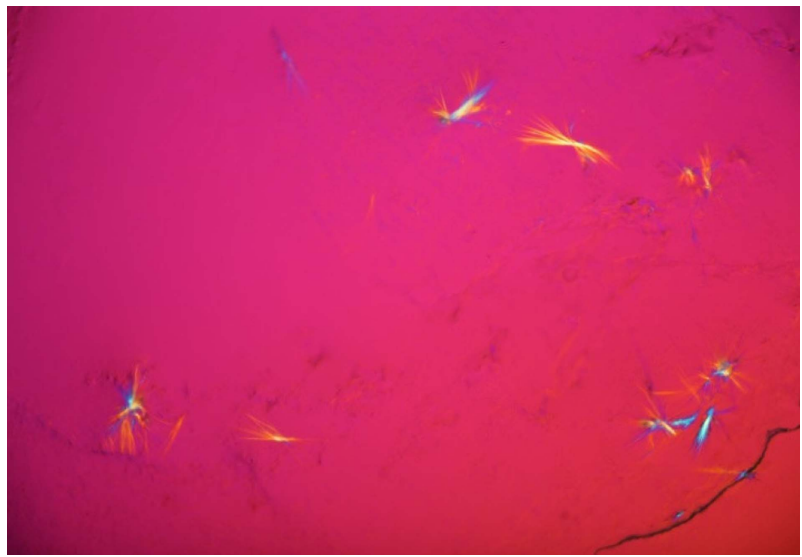

Figure 4 Positively and negatively birefringent crystals within the prostate gland lumen.

specific, and with the introduction of polarising microscopy, this stain is no longer regularly applied in practice. ${ }^{46}$ We mention this experience because the long-standing hyperuricaemia and abundant tophi in this man with a long history of repeated gouty arthritis made that diagnosis undeniable. We acknowledge that not all of the crystals we have found may be MSU monohydrate. Urates aside from MSU, including calcium urate, potassium urate and magnesium urate, are known to form within the urinary tract leading to renal calculi ${ }^{47} 48$ and could be contributing to this other type of crystal seen in renal tophi and other tissues as well. Additionally, urate is a well-known chelator of metal ions such as zinc, copper and iron, and may form salts of metallourate complexes. ${ }^{49}{ }^{50}$ It remains unclear whether such complexes might form birefringent crystals, though.

The great majority of the crystals we found in prostates were morphologically identical to those we expect to see in gouty joints. Although none of the prostates we examined were obtained from patients with a recognised history of gout or hyperuricaemia, we believe this may not be accurate. Most of these men were referred to our urologists from outside our hospital system, and the exact prevalence of gout and hyperuricaemia may not have been reflected in the medical record.

We chose to study prostates because they are so often afflicted with chronic inflammation, and we had access to a large repository of prostate tissues. Each specimen was frozen and thus had not seen the formalin fixation that dissolves most tissue urate before the pathologist ever sees the slides. All of these specimens also contained malignant areas, but no control prostates were examined. Our data cannot be taken as indicative of a causal link between crystals and cancer.

A potential mechanism of prostatic crystal deposition could be due to the reflux of urine supersaturated with uric acid. However, the crystal morphology we observed was the classic needle shape of urate, rather than uric acid, which is generally diamond-shaped or barrel-shaped. Irrespective of its source, the presence of so many urate crystals strongly suggests the possibility that some, much or most prostatitis is crystal-driven. Given the highly effective armamentarium with which we now fight gout, the investigational opportunities are obvious as is the hope that such medications may be found of use in the management of this frustrating problem.

Only a small percentage of aortic valves in this study contained birefringent crystals, thus reinforcing the concept that most of the apparently 'tophaceous' deposits at this site are calcific. MSU crystals are unlikely to be a significant contributor to aortic valve disease, but the possibility continues to merit consideration in the hyperuricaemic patient with tophi elsewhere.

Over the years, the conception of gout has evolved away from that of a periodic nuisance that sometimes could be damaging. Instead, it is increasingly clear that this is a progressive, systemic disease with a panoply of injurious manifestations throughout the body. We hope that our small pilot study will encourage others to examine the epidemiology of urate deposition as well as the consequences of such deposits throughout the body. Undissociated uric acid, rather than the sodium urate of gouty arthritis, has been recognized as a damage-associated signal, ${ }^{51}{ }^{52}$ and there has been debate about whether uric acid is an active or inert participant in tissue injury. In this study, we found that MSU crystals are present in coronary arteries and prostates, suggestive that they may play a role as a trigger for the NALP3 inflammasome pathway, just as they do within the joint. Further studies are warranted to investigate the consequences to MSU crystals within these tissues.

Acknowledgements The authors would like to thank Ruikang Wang, for deconvolution microscopy expertise, Robert Vessella, for access to his repository of malignant prostate samples, Kevin O'Brien, for access to his repository of coronary arteries and Claire Hagger for pathology assistance.

Contributors JJP performed polarising microscopy, a chart review and drafted the manuscript. MR provided prostate pathology expertise. DS collected tissue samples and performed polarising microscopy. NAM provided cardiac tissue samples. PS conceived, designed the study and drafted the manuscript. All authors read and approved the final manuscript.

Funding This research received support from Takeda Pharmaceuticals (MSA-COL-104). No other funding source was involved.

Competing interests Study implementation and salary support for Jane Park and Peter Simkin were provided by Takeda Pharmaceuticals.

Ethics approval University of Washington IRB.

Provenance and peer review Not commissioned; externally peer reviewed.

Data sharing statement There are several photos of crystals within prostates that were not included. Photos of the crystals of the one aortic valve were not included. Photos are available by emailing janepark@uw.edu

Open Access This is an Open Access article distributed in accordance with the Creative Commons Attribution Non Commercial (CC BY-NC 4.0) license, which permits others to distribute, remix, adapt, build upon this work noncommercially, and license their derivative works on different terms, provided the original work is properly cited and the use is non-commercial. See: http:// creativecommons.org/licenses/by-nc/4.0/ 


\section{REFERENCES}

1. Forbess LJ, Fields TR. The broad spectrum of urate crystal deposition: unusual presentations of gouty tophi. Semin Arthritis Rheum 2012;42:146-54

2. Weiss TE, Segaloff A. Gouty arthritis and gout: an ancient disease with modern interest. Springfield, IL: Thomas, 1959.

3. Dalbeth N, Kalluru R, Aati O, et al. Tendon involvement in the feet of patients with gout: a dual-energy CT study. Ann Rheum Dis 2013;72:1545-8.

4. Gruber M, Bodner G, Rath E, et al. Dual-energy computed tomography compared with ultrasound in the diagnosis of gout. Rheumatology (Oxford) 2013;72:1545-8.

5. McQueen FM, Reeves Q, Dalbeth N. New insights into an old disease: advanced imaging in the diagnosis and management of gout. Postgrad Med J 2013;89:87-93.

6. Feig DI, Kang DH, Johnson RJ. Uric acid and cardiovascular risk. N Engl J Med 2008;359:1811-21.

7. loachimescu AG, Brennan DM, Hoar BM, et al. Serum uric acid is an independent predictor of all-cause mortality in patients at high risk of cardiovascular disease: a preventive cardiology information system (PreCIS) database cohort study. Arthritis Rheum 2008 58:623-30.

8. Kuo CF, See LC, Luo SF, et al. Gout: an independent risk factor for all-cause and cardiovascular mortality. Rheumatology (Oxford) 2010;49:141-6.

9. Moriarity JT, Folsom AR, Iribarren C, et al. Serum uric acid and risk of coronary heart disease: Atherosclerosis Risk in Communities (ARIC) Study. Ann Epidemiol 2000;10:136-43.

10. Krishnan E, Pandya BJ, Chung L, et al. Hyperuricemia and the risk for subclinical coronary atherosclerosis-data from a prospective observational cohort study. Arthritis Res Ther 2011;13:R66.

11. Choi HK, Curhan G. Independent impact of gout on mortality and risk for coronary heart disease. Circulation 2007;116:894-900.

12. De Vera MA, Rahman MM, Bhole V, et al. Independent impact of gout on the risk of acute myocardial infarction among elderly women: a population-based study. Ann Rheum Dis 2010; 69:1162-4.

13. Chen JH, Chuang SY, Chen $\mathrm{HJ}$, et al. Serum uric acid level as an independent risk factor for all-cause, cardiovascular, and ischemic stroke mortality: a Chinese cohort study. Arthritis Rheum 2009;61:225-32

14. Lichtman AH, Binder CJ, Tsimikas S, et al. Adaptive immunity in atherogenesis: new insights and therapeutic approaches. J Clin Invest 2013;123:27-36.

15. Stoll G, Bendszus M. Inflammation and atherosclerosis: novel insights into plaque formation and destabilization. Stroke 2006;37:1923-32.

16. Legein B, Temmerman L, Biessen EA, et al. Inflammation and immune system interactions in atherosclerosis. Cell Mol Life Sci 2013;70:3847-69.

17. Moore KJ, Tabas I. Macrophages in the pathogenesis of atherosclerosis. Cell 2011;145:341-55.

18. Weber $\mathrm{C}$, Noels $\mathrm{H}$. Atherosclerosis: current pathogenesis and therapeutic options. Nat Med 2011;17:1410-22.

19. Hansson GK, Hermansson A. The immune system in atherosclerosis. Nat Immunol 2011;12:204-12.

20. Martinon F, Petrilli V, Mayor A, et al. Gout-associated uric acid crystals activate the NALP3 inflammasome. Nature 2006;440:237-41.

21. Traut EF, Knight $A A$, Szanto $P B$, et al. Specific vascular changes in gout. JAMA 1954;156:591-3.

22. McCarty DJ, Hollander JL. Identification of urate crystals in gouty synovial fluid. Ann Intern Med 1961;54:452-60.

23. Dennstedt FE, Weilbaecher DG. Tophaceous mitral value: report of a case. Am J Surg Pathol 1982;6:79-81.

24. Jaworski RC, Gibson M. Tophaceous aortic valve: a case report Pathology 1983;15:197-9.

25. Curtiss EI, Miller TR, Shapiro LS. Pulmonic regurgitation due to valvular tophi. Circulation 1983;67:699-701

26. Scalapino JN, Edwards WD, Steckelberg JM, et al. Mitral stenosis associated with valvular tophi. Mayo Clin Proc 1984;59:509-12.
27. Gawoski JM, Balogh K, Landis WJ. Aortic valvular tophus: identification by $\mathrm{X}$-ray diffraction of urate and calcium phosphates. J Clin Pathol 1985;38:873-6.

28. lacobellis $\mathrm{G}$. A rare and asymptomatic case of mitral valve tophus associated with severe gouty tophaceous arthritis. J Endocrinol Invest 2004;27:965-6.

29. Go AS, Mozaffarian D, Roger VL, et al. Heart disease and stroke statistics-2013 update: a report from the American Heart Association. Circulation 2013;127:e6-e245.

30. Stewart BF, Siscovick D, Lind BK, et al. Clinical factors associated with calcific aortic valve disease. Cardiovascular Health Study. J Am Coll Cardiol 1997;29:630-4.

31. Katz R, Wong ND, Kronmal R, et al. Features of the metabolic syndrome and diabetes mellitus as predictors of aortic valve calcification in the Multi-Ethnic Study of Atherosclerosis. Circulation 2006;113:2113-19.

32. Demir B, Caglar IM, Ugurlucan M, et al. The relationship between severity of calcific aortic stenosis and serum uric acid levels. Angiology 2012;63:603-8.

33. Krieger JN, Riley DE, Cheah PY, et al. Epidemiology of prostatitis: new evidence for a world-wide problem. World J Urol 2003;21:70-4.

34. Pontari MA. Chronic prostatitis/chronic pelvic pain syndrome. Urol Clin North Am 2008;35:81-9; vi.

35. True LD, Berger RE, Rothman I, et al. Prostate histopathology and the chronic prostatitis/chronic pelvic pain syndrome: a prospective biopsy study. J Urol 1999;162:2014-18.

36. Hochreiter WW, Nadler RB, Koch AE, et al. Evaluation of the cytokines interleukin 8 and epithelial neutrophil activating peptide 78 as indicators of inflammation in prostatic secretions. Urology 2000;56:1025-9.

37. Nadler RB, Koch AE, Calhoun EA, et al. IL-1beta and TNF-alpha in prostatic secretions are indicators in the evaluation of men with chronic prostatitis. J Urol 2000;164:214-18.

38. Persson BE, Ronquist G. Evidence for a mechanistic association between nonbacterial prostatitis and levels of urate and creatinine in expressed prostatic secretion. J Urol 1996;155:958-60.

39. Persson BE, Ronquist G, Ekblom M. Ameliorative effect of allopurinol on nonbacterial prostatitis: a parallel double-blind controlled study. J Urol 1996;155:961-4.

40. Linnane JW, Burry AF, Emmerson BT. Urate deposits in the renal medulla. Prevalence and associations. Nephron 1981:29:216-22.

41. Talbott JH. Gout. New York: Grune \& Stratton, 1957.

42. Wall B, Agudelo CA, Tesser JR, et al. An autopsy study of the prevalence of monosodium urate and calcium pyrophosphate dihydrate crystal deposition in first metatarsophalangeal joints. Arthritis Rheum 1983;26:1522-4.

43. Simkin PA, Bassett JE, Lee QP. Not water, but formalin, dissolves urate crystals in tophaceous tissue samples. J Rheum 1994;21:2320-1.

44. Sen B, Arora VK, Gupta K, et al. Platelike urate crystals in gouty tophi. Acta Cytol 1993;37:640-1.

45. Spitz $\mathrm{H}$, Steinbrocker O. Fulminating fatal gout. Am J Med 1949;6:513-21.

46. Shidham V, Shidham G. Staining method to demonstrate urate crystals in formalin-fixed, paraffin-embedded tissue sections. Arch Pathol Lab Med 2000;124:774-6.

47. Herring LC. Observations on the analysis of ten thousand urinary calculi. J Urol 1962:88:545-62.

48. Bellanato J, Cifuentes JL, Salvador E, et al. Urates in uric acid renal calculi. Int J Urol 2009;16:318-21; discussion 22.

49. Fleckenstein JL, Simkin PA. Zinc-mediated urate binding to human albumin. Adv Exp Med Biol 1986;195(Pt A):345-9.

50. Mascitelli L, Pezzetta F, Goldstein MR. Comment on: gout: an independent risk factor for all-cause and cardiovascular mortality. Rheumatology (Oxford) 2010;49:1421-2; author reply 2.

51. Shi Y, Evans JE, Rock KL. Molecular identification of a danger signal that alerts the immune system to dying cells. Nature 2003;425:516-21.

52. Kono $\mathrm{H}$, Chen $\mathrm{CJ}$, Ontiveros F, et al. Uric acid promotes an acute inflammatory response to sterile cell death in mice. J Clin Invest 2010;120:1939-49. 